\title{
Inferior Epigastric Artery
}

National Cancer Institute

\section{Source}

National Cancer Institute. Inferior Epigastric Artery. NCI Thesaurus. Code C52861.

A blood vessel arising from the external iliac artery with many smaller branches that connects to the superior epigastric artery and lower intercostal arteries. 